\title{
Voltage stability in low voltage microgrids in aspects of active and reactive power demand
}

\author{
MirosŁaW PAROL, LUKASZ RoKICKI \\ Warsaw University of Technology \\ Institute of Electrical Power Engineering \\ ul. Koszykowa 75, 00-662 Warszawa, Poland \\ e-mail: \{miroslaw.parol/lukasz.rokicki\}@ien.pw.edu.pl
}

(Received: 07.01.2015, revised: 12.05.2015)

\begin{abstract}
Low voltage microgrids are autonomous subsystems, in which generation, storage and power and electrical energy consumption appear. In the paper the main attention has been paid to the voltage stability issue in low voltage microgrid for different variants of its operation. In the introduction a notion of microgrid has been presented, and also the issue of influence of active and reactive power balance on node voltage level has been described. Then description of voltage stability issue has been presented. The conditions of voltage stability and indicators used to determine voltage stability margin in the microgrid have been described. Description of the low voltage test microgrid, as well as research methodology along with definition of considered variants of its operation have been presented further. The results of exemplary calculations carried out for the daily changes in node load of the active and reactive power, i.e. the voltage and the voltage stability margin indexes in nodes have been presented. Furthermore, the changes of voltage stability margin indexes depending on the variant of the microgrid operation have been presented. Summary and formulation of conclusions related to the issue of voltage stability in microgrids have been included at the end of the paper.
\end{abstract}

Key words: distributed generation, microgrids, voltage stability, voltage stability margin indexes

\section{Introduction}

Low voltage (LV) microgrids are autonomous subsystems, in which generation, storage as well as power and electrical energy consumption appear [1-3]. Microsources, energy storage units and controllable loads are connected to microgrid via local controllers (microsources controllers, energy storage unit controllers and load controllers). Microgrid can operate in synchronous mode with network of Distribution System Operator (DSO) or in island mode. One of the essential problems is to develop proper control strategies in microgrids, i.e. algorithms for setting the operating points of microsources, energy storage units and controllable loads [4-7].

In the paper the main attention has been paid to the voltage stability issue in low voltage microgrid. Voltage level in given node of electric power network is strictly connected with reactive power balance. Power system (microgrids) is voltage stable if reactive power deli- 
vered to the one is equal to reactive power consumed by loads located in this system. Loss of voltage stability in power system is connected most often with abrupt decrease of voltages in particular nodes [8].

Issue of voltage stability in microgrid was described in [9]. In this paper as key problems for consideration during analysis of microgrid stability were pointed: strategy of reactive power regulation, characteristics of possible to appear loads, possible increase of power demand, ability of electric power network to work in case of failure of any network element. In paper [10] model of voltage stabilizer, which enables improvement of microgrid voltage stability, was presented. Microgrid voltage stabilizer sends control signals to reactive power sources according to their power capacities for the improvement of the voltage stability in microgrid. Microgrid voltage stability issue was also described in [11]. The results of measurements in microgrid fed from network of DSO via power electronic converter were presented there. The microgrid serves for feeding holiday cottages. Such solution can allow for improving microgrid voltage stability.

Purpose of the paper is to investigate two voltage stability margin indexes, based on load characteristics QU and PU diagrams and to determine possibility of their use in analysis of microgrid operation both in synchronous mode and in island mode as well.

Presented results of investigations can have practical meaning for subjects interested in LV microgrids, especially for the ones interested in voltage stability in microgrids.

The following sections: description of voltage stability issue, description of a test microgrid and research methodology, exemplary calculations results as well as summary and conclusions have been presented in further part of the paper.

\section{Description of voltage stability issue}

Loss of voltage stability in electric power system appears in case of lack of balance between delivered and consumed reactive power, i.e. when reactive power delivered is smaller than reactive power consumed [8].

Different voltage stability conditions are distinguished in [8]:

- condition

$$
\frac{d(\Delta Q)}{d U}<0,
$$

where $\Delta Q$ is difference between reactive power delivered, and reactive power consumed,

- condition

$$
\frac{d E}{d U}>0,
$$

where $E$ is value of electromotive force of source representing electric power system, - condition

$$
\frac{Q_{s}}{d Q_{L}}>0
$$


where $Q_{s}$ is reactive power delivered by source, and $Q_{L}$ is reactive power consumed by load.

Difference between stable balance point and critical point (i.e. such point, in which appears loss of voltage stability - like an avalanche decrease of voltage) is determined as voltage stability margin. This point corresponds with critical voltage $U_{c r i t}$ and critical reactive power $Q\left(U_{\text {crit }}\right)$.

Voltage stability margin indexes (indicators) have been described in [8] in detail.

Evaluation of voltage stability in chosen microgrid nodes can be made using the indicators based on [8]:

- load characteristics on $Q U$ diagram - plot reactive power $(Q)$ as a function of voltage $(U)$,

- load characteristics on $P U$ diagram - plot active power $(P)$ as a function of voltage $(U)$.

Both of the proposed approaches require to specify the maximum (critical) value of active and reactive power that the microgrid node may be loaded with. After determining the maximum power that can be charged to the node, voltage stability margin indicators $k_{Q U}$ and $k_{P U}$ are calculated according to the following formulae [8]:

$$
\begin{aligned}
& k_{Q U}=\frac{Q\left(U_{\text {crit }}\right)-Q_{0}}{Q\left(U_{\text {crit }}\right)} \cdot 100 \%, \\
& k_{P U}=\frac{P\left(U_{\text {crit }}\right)-P_{0}}{P\left(U_{\text {crit }}\right)} \cdot 100 \%,
\end{aligned}
$$

where: $Q\left(U_{\text {crit }}\right)$ - maximum value of reactive power that are permissible in the node, $Q_{0}$ - current value of reactive power, $P\left(U_{c r i t}\right)$ - maximum value of active power that are permissible in the node, $P_{0}$ - current value of active power.

Microgrid node is voltage stable when the $k_{Q U}$ and $k_{P U}$ indicators reach values greater than zero. If the values of proposed indicators are greater, the voltage stability margin is greater.

\section{Description of a test microgrid and research methodology}

This paper focuses on testing voltage stability of low voltage microgrid that is a modification of the grid described in [12]. The modifications that were introduced involved choosing such microsources that would enable proper operation of the microgrid both when it is connected to a network of DSO or when it is in the island mode. Key diagram of the test microgrid, prepared with the use of PowerFactory 14.1 software [13], is shown in Figure 1.

The following generating units (microsources) were installed in the microgrid: photovoltaic cells, fuel cell, wind microturbines and gas microturbine. The reference source that determines rated voltage and grid operating frequency in the island mode is the diesel power generator set supported by a battery energy storage. Modeling of microsources was based on [14]. Symbols of energy storage and photovoltaic cells, presented in Figure 1, represent the generating unit and power electronic converter that connects the generating unit to the microgrid. Wind microturbines were modeled as static generators set in a way to simulate the operation of an asynchronous machine. Fuel cells and gas microturbine represent the DC sources 
connected to the grid through power electronic converters. A list of basic parameters of microsources is shown in Table 1.

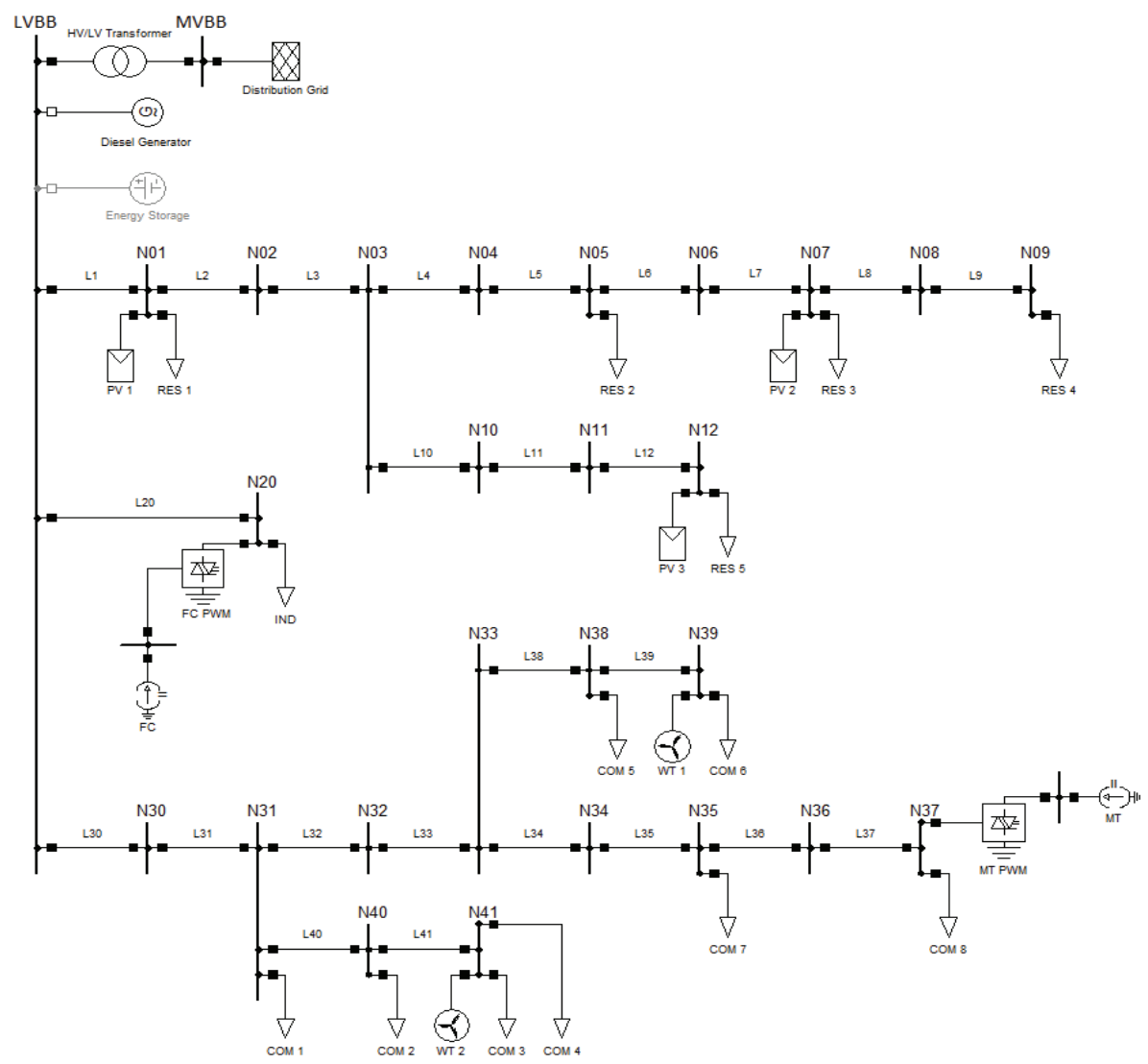

Fig. 1. Key diagram of the test microgrid (LVBB - low voltage busbar, MVBB - medium voltage busbar, PV - photovoltaic cell, FC - fuel cell, MT - gas microturbine, WT - wind microturbine, RES - residential load, IND - industrial load, COM - commercial load); prepared on the basis of $[12,14,15]$

Table 1. Basic parameters of the microsources included in the microgrid; elaborated on the basis of [15]

\begin{tabular}{l|c|c|c|c}
\hline \multicolumn{1}{c|}{ Type of source } & Symbol & $\boldsymbol{P}_{\boldsymbol{N}}[\mathbf{k W}]$ & $\boldsymbol{Q}_{\boldsymbol{N}}[\mathbf{k v a r}]$ & Node \\
\hline \multirow{3}{*}{ Photovoltaic cell } & PV 1 & 10.0 & 0.0 & N01 \\
\cline { 2 - 5 } & PV 2 & 10.0 & 0.0 & N07 \\
\cline { 2 - 5 } & PV 3 & 20.0 & 0.0 & N12 \\
\hline \multirow{2}{*}{ Wind microturbine* } & WT 1 & 10.0 & 7.5 & N39 \\
\cline { 2 - 5 } & WT 2 & 20.0 & 15.0 & N41 \\
\hline Gas microturbine & MT & 50.0 & 19.8 & N37 \\
\hline Fuel cell & FC & 25.0 & 0.0 & N20 \\
\hline Diesel power generator set & diesel generator & 160.0 & 120.0 & LVBB \\
\hline
\end{tabular}

* - wind microturbine consumes inductive reactive power 
Active and reactive power from the external distribution network (network of DSO), and generated in microsources will be consumed by the following 3 categories of consumers:

- residential consumers (RES),

- industrial consumers (IND),

- commercial consumers (COM).

Each of the above categories of consumers is characterized by different daily active power load profiles, as shown in Table 2.

Table 2. Daily load profiles for different types of loads; elaborated on the basis of $[12,14]$

\begin{tabular}{c|c|c|c}
\hline $\boldsymbol{t}$ & \multicolumn{3}{|c}{$\boldsymbol{P}[\boldsymbol{\%}]$} \\
\hline$[\mathbf{h}]$ & $\mathbf{R E S}$ & $\mathbf{C O M}$ & IND \\
\hline 0 & 30 & 23 & 35 \\
\hline 1 & 28 & 21 & 33 \\
\hline 2 & 25 & 19 & 30 \\
\hline 3 & 22 & 22 & 27 \\
\hline 4 & 20 & 23 & 25 \\
\hline 5 & 20 & 24 & 30 \\
\hline 6 & 22 & 25 & 38 \\
\hline 7 & 30 & 36 & 54 \\
\hline 8 & 39 & 49 & 75 \\
\hline 9 & 41 & 63 & 88 \\
\hline 10 & 44 & 79 & 100 \\
\hline 11 & 49 & 85 & 100 \\
\hline 12 & 49 & 90 & 90 \\
\hline 13 & 54 & 92 & 100 \\
\hline 14 & 59 & 93 & 100 \\
\hline 15 & 59 & 87 & 95 \\
\hline 16 & 54 & 85 & 90 \\
\hline 17 & 59 & 90 & 75 \\
\hline 18 & 63 & 100 & 60 \\
\hline 19 & 84 & 80 & 55 \\
\hline 20 & 100 & 69 & 49 \\
\hline 21 & 90 & 60 & 45 \\
\hline 22 & 90 & 50 & 40 \\
\hline 23 & 54 & 30 & 38 \\
\hline & & &
\end{tabular}

Detailed values of active and reactive peak load and the power factor $\cos \varphi$ of individual consumers are presented in Table 3.

Microsources, MV/LV transformer functioning as the connection between the microgrid and the network of DSO, and individual consumers are connected through low voltage lines operating in the TN-C system. Parameters of the electric power lines are presented in Table 4. During the calculation process of voltage stability margin indexes it is assumed that the fuel cell operates at constant power equal to rated power, while power generated by wind microturbines and photovoltaic cells is subject to daily changes, as shown on Figures 2 and 3. 
The gas microturbine capacity will be variable depending on the chosen variant of microgrid operation.

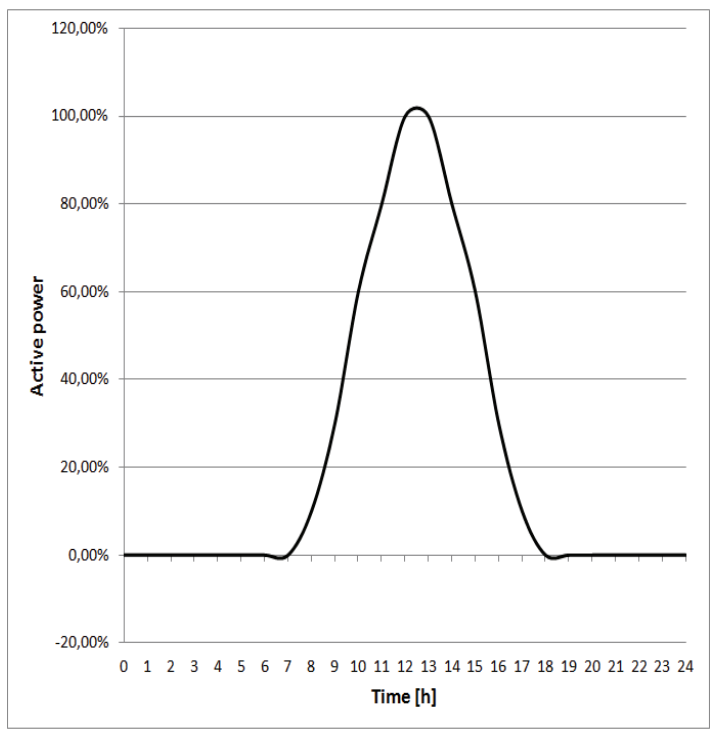

Fig. 2. Daily profile of active power generation of a photovoltaic cell [15]

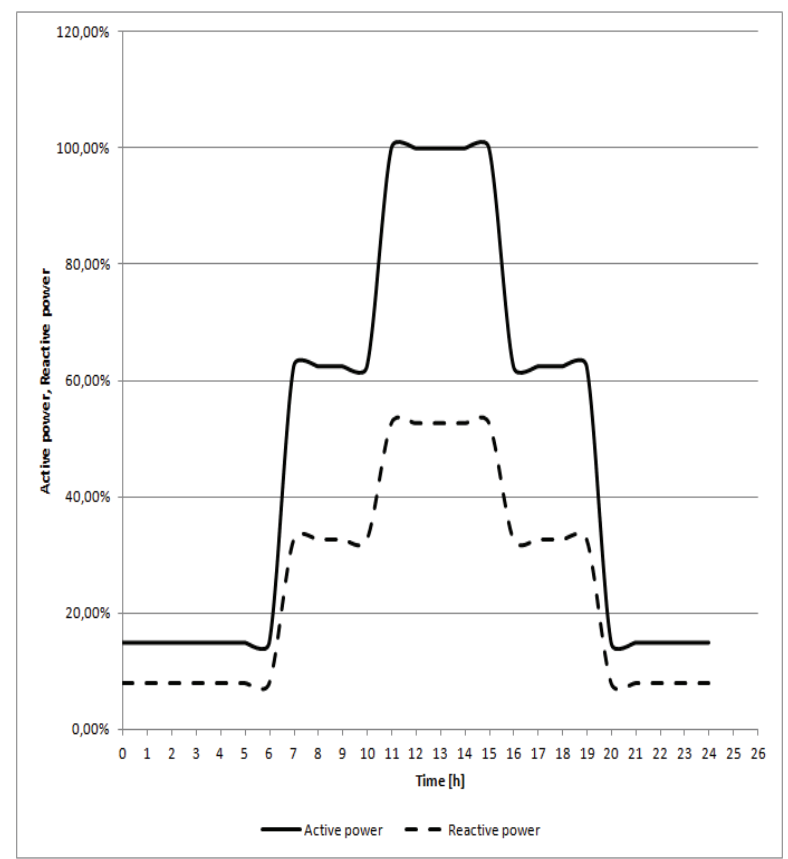

Fig. 3. Daily profile of active power generation and reactive power consumption of a wind microturbine [15] 
Tests of voltage stability were conducted on the described model LV test microgrid, in which all necessary calculations are made. Evaluation of voltage stability in chosen microgrid nodes was made using the defined earlier indicators.

For both voltage stability margin indicators, it is required to determine the maximum value of active and reactive power that the microgrid node may be loaded with. For that purpose, a simulation of gradual node loading with active power only, reactive power only and with constant value of power factor $\cos \varphi$ is made. Loading is continued until the message about the loss of convergence of the load flow iterative process shows up.

In order to consider different kinds of microgrid operations, calculations were made for the following variants:

- V0 - all microsources are shut down and the microgrid is supplied from the network of DSO only,

- V1 - the microgrid is connected to the network of DSO, all types of microsources are in operation and the microturbine operates with power equal to rated power,

- V2 - the microgrid is connected to the network of DSO, all types of microsources are in operation and the microturbine operates with power equal to $40 \%$ of rated power,

- V3 - microgrid is connected to the network of DSO, microturbine is shut down and the remaining microsources are in operation,

- V4 - the microgrid operates in the island mode, all types of microsources are in operation and the microturbine operates with power equal to rated power,

- V5 - the microgrid operates in the island mode, all types of microsources are in operation and the microturbine operates with power equal to $40 \%$ of rated power,

- V6 - the microgrid operates in the island mode, microturbine is shut down and the remaining microsources are in operation.

Results of calculations made with respect to V0 variant will be treated as reference values in order to evaluate the voltage stability of the microgrid in case of operation in one of the remaining variants.

Table 3. Active and reactive peak load of individual consumers; elaborated on the basis of $[12,14]$

\begin{tabular}{|c|c|c|c|c|c|}
\hline Type of load & Symbol & $P_{L}[\mathrm{~kW}]$ & $Q_{L}$ [kvar] & $\cos \varphi$ & Node \\
\hline \multirow{5}{*}{$\begin{array}{l}\text { Residential } \\
\text { consumer }\end{array}$} & RES 1 & 15.000 & 4.930 & 0.95 & N01 \\
\hline & RES 2 & 55.000 & 18.078 & 0.95 & N05 \\
\hline & RES 3 & 15.000 & 4.930 & 0.95 & N07 \\
\hline & RES 4 & 37.000 & 12.161 & 0.95 & N09 \\
\hline & RES 5 & 32.000 & 10.518 & 0.95 & N12 \\
\hline Industrial consumer & IND & 70.000 & 27.666 & 0.93 & $\mathrm{~N} 20$ \\
\hline \multirow{8}{*}{$\begin{array}{l}\text { Commercial } \\
\text { consumer }\end{array}$} & COM 1 & 30.000 & 8.750 & 0.96 & N31 \\
\hline & COM 2 & 26.000 & 7.583 & 0.96 & $\mathrm{~N} 40$ \\
\hline & $\mathrm{COM} 3$ & 8.000 & 2.333 & 0.96 & N41 \\
\hline & $\mathrm{COM} 4$ & 20.000 & 5.833 & 0.96 & N41 \\
\hline & COM 5 & 16.000 & 4.667 & 0.96 & N38 \\
\hline & COM 6 & 8.000 & 2.333 & 0.96 & N39 \\
\hline & COM 7 & 26.000 & 7.583 & 0.96 & N35 \\
\hline & COM 8 & 20.000 & 5.833 & 0.96 & N37 \\
\hline
\end{tabular}


Table 4. Parameters of LV power lines; based on $[12,14]$

\begin{tabular}{|c|c|c|c|c|c|c|}
\hline Line & Type & $R^{\prime}[\Omega / \mathbf{k m}]$ & $X^{\prime}[\mathbf{\Omega} / \mathbf{k m}]$ & $B^{\prime}[\mu \mathbf{S} / \mathbf{k m}]$ & $I_{z}[\mathrm{~A}]$ & $L[\mathbf{m}]$ \\
\hline L1 & AsXS $4 \times 120$ & 0.2530 & 0.0591 & 25.1905 & 280 & 35 \\
\hline L2 & AsXS $4 \times 120$ & 0.2530 & 0.0591 & 25.1905 & 280 & 35 \\
\hline L3 & AsXS $4 \times 120$ & 0.2530 & 0.0591 & 25.1905 & 280 & 35 \\
\hline L4 & AsXS $4 \times 120$ & 0.2530 & 0.0591 & 25.1905 & 280 & 35 \\
\hline L5 & AsXS $4 \times 120$ & 0.2530 & 0.0591 & 251905 & 280 & 35 \\
\hline L6 & AsXS $4 \times 120$ & 0.2530 & 0.0591 & 25.1905 & 280 & 35 \\
\hline L7 & AsXS $4 \times 120$ & 0.2530 & 0.0591 & 25.1905 & 280 & 35 \\
\hline L8 & AsXS $4 \times 120$ & 0.2530 & 0.0591 & 25.1905 & 280 & 35 \\
\hline L9 & AsXS $4 \times 120$ & 0.2530 & 0.0591 & 25.1905 & 280 & 35 \\
\hline L10 & AsXS $4 \times 70$ & 0.4430 & 0.0591 & 25.1905 & 195 & 35 \\
\hline L11 & AsXS $4 \times 70$ & 0.4430 & 0.0591 & 25.1905 & 195 & 35 \\
\hline $\mathrm{L} 12$ & AsXS $4 \times 70$ & 0.4430 & 0.0591 & 25.1905 & 195 & 35 \\
\hline L20 & YAKY $4 \times 150$ & 0.2060 & 0.0737 & 188.8360 & 270 & 200 \\
\hline L31 & $4 \times \mathrm{Al} 50$ & 0.5917 & 0.2888 & 4.0041 & 225 & 30 \\
\hline L32 & $4 \times \mathrm{Al} 50$ & 0.5917 & 0.2888 & 4.0041 & 225 & 30 \\
\hline L33 & $4 \times \mathrm{Al} 50$ & 0.5917 & 0.2888 & 4.0041 & 225 & 30 \\
\hline L34 & $4 \times \mathrm{A} 135$ & 0.8385 & 0.2997 & 3.8560 & 180 & 30 \\
\hline L35 & $4 \times \mathrm{Al} 35$ & 0.8385 & 0.2997 & 3.8560 & 180 & 30 \\
\hline L36 & $4 \times \mathrm{Al} 35$ & 0.8385 & 0.2997 & 3.8560 & 180 & 30 \\
\hline L37 & $4 \times \mathrm{Al} 35$ & 0.8385 & 0.2997 & 3.8560 & 180 & 30 \\
\hline L38 & $4 \times \mathrm{Al} 16$ & 1.8220 & 0.2404 & 3.5518 & 110 & 30 \\
\hline L39 & $4 \times \mathrm{Al} 16$ & 1.8220 & 0.2404 & 3.5518 & 110 & 30 \\
\hline L40 & $4 \times \mathrm{Al} 35$ & 0.8385 & 0.2997 & 3.8560 & 180 & 30 \\
\hline L41 & $4 \times \mathrm{Al} 35$ & 0.8385 & 0.2997 & 3.8560 & 180 & 30 \\
\hline
\end{tabular}

Remark. Line L20 is represented by underground cable. Other electric power lines represent overhead lines.

\section{Exemplary calculations results}

Calculations of voltage stability margin were made for several chosen nodes of the test microgrid. The diagrams presented in this paper show daily voltage changes in nodes (Figs. 4-5) and changes in the voltage stability margin indicators $k_{Q U}$ and $k_{P U}$ (Figs. 6-9). 


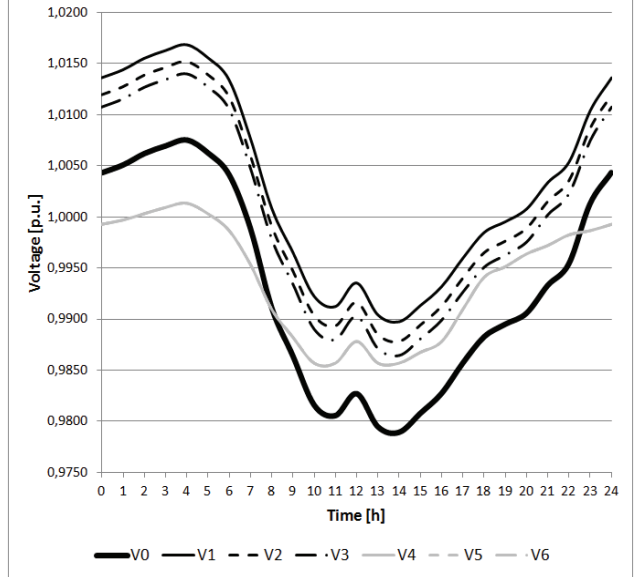

Fig. 4. Daily voltage changes in node N20 for particular variants (note: curves corresponding to variants $\mathrm{V} 4, \mathrm{~V} 5$ and $\mathrm{V} 6$ are coincident)

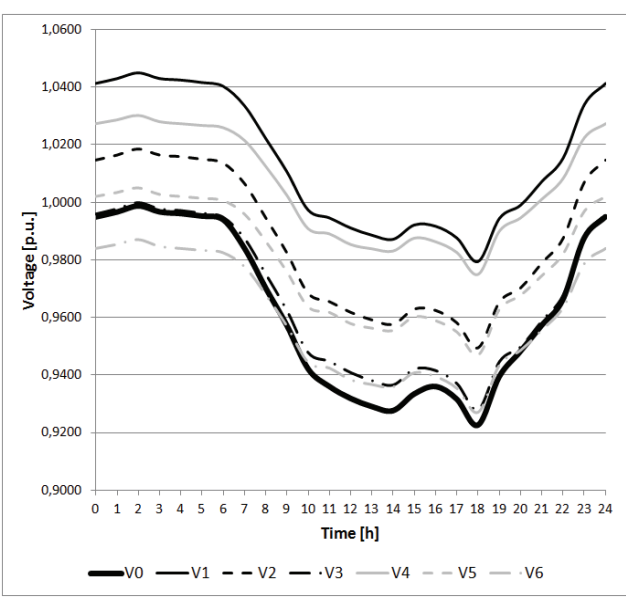

Fig. 5. Daily voltage changes in node N35 for particular variants

To better illustrate the influence of the way of microsources operation and microgrid operation mode, changes in the voltage stability margin indicators (for different hours) depending on the chosen operation variant, in relation to V0 variant, were presented in Figures 10-13. The calculations were made with assumption that node load changes with constant power factor $\cos \varphi$. Presented Figures 10-13 clearly show that the reduction of power generated by microsources reduces the voltage stability margin indicators $k_{Q U}$ and $k_{P U}$. Synchronous operation of the microgrid including microsources and distribution grid results in a slight increase

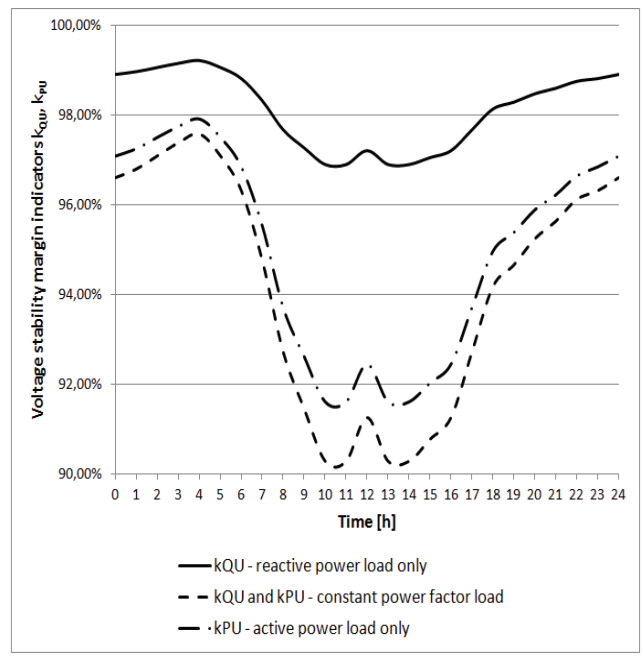

Fig. 6. Daily changes of $k_{Q U}$ and $k_{P U}$ indicators in node N20 - variant V3

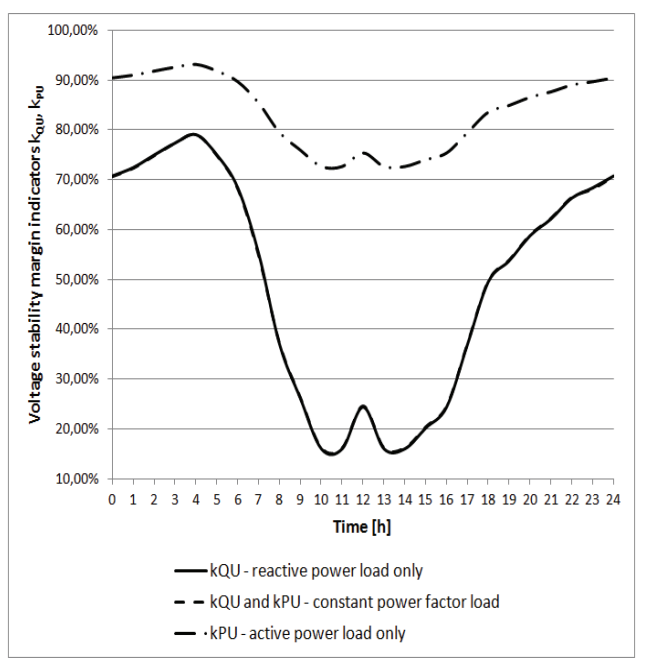

Fig. 7. Daily changes $k_{Q U}$ and $k_{P U}$ indicators in node N20 - variant V6 (note: curves corresponding to variants with reactive power load only and constant power factor load are coincident) 


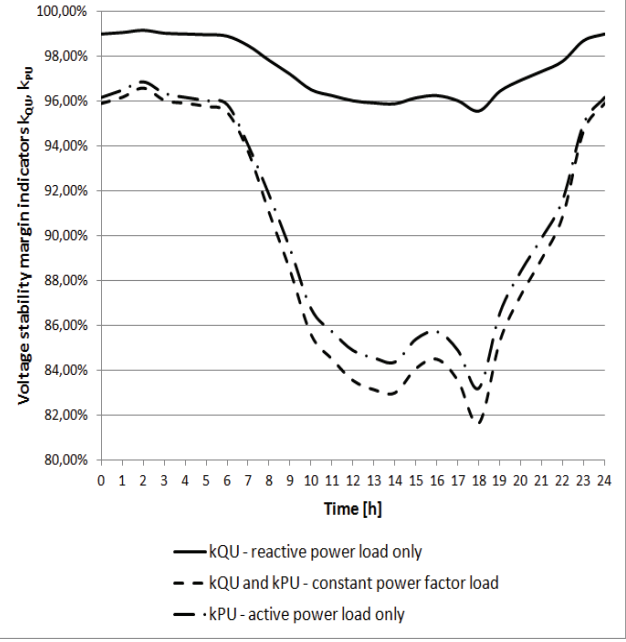

Fig. 8. Daily changes $k_{Q U}$ and $k_{P U}$ indicators in node N35 - variant V3

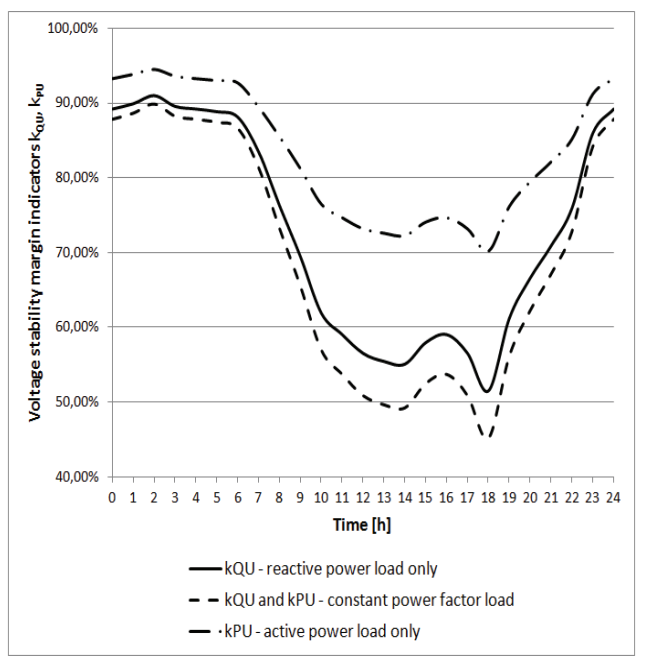

Fig. 9. Daily changes $k_{Q U}$ and $k_{P U}$ indicators in node N35 - variant V6

of voltage stability margin in comparison to the variant in which analyzed low voltage microgrid is passive.Transition of microgrid from synchronous to island mode results in a high reduction of voltage stability margin, due to the limited possibilities of power generation of microsources. The degree of change in the values of analyzed indicators is directly proportional to the power demand of customers. The greatest fluctuations of voltage stability margin indicators were recorded in 12 and 18 hours of a day, when power demand is high. In the situation when power demand was low ( 0 and 6 hours of a day), differences in the values of voltage stability margin indicators were lower.

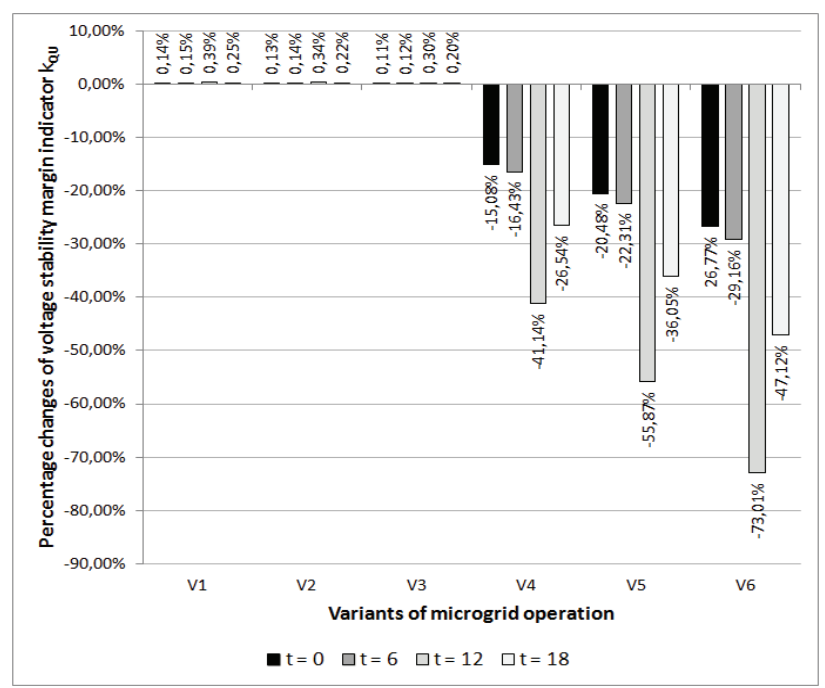

Fig. 10. Percentage changes in the indicator $k_{Q U}$ value of node $N 20$ depending on the chosen microgrid operation variant in relation to $\mathrm{V} 0$ variant 


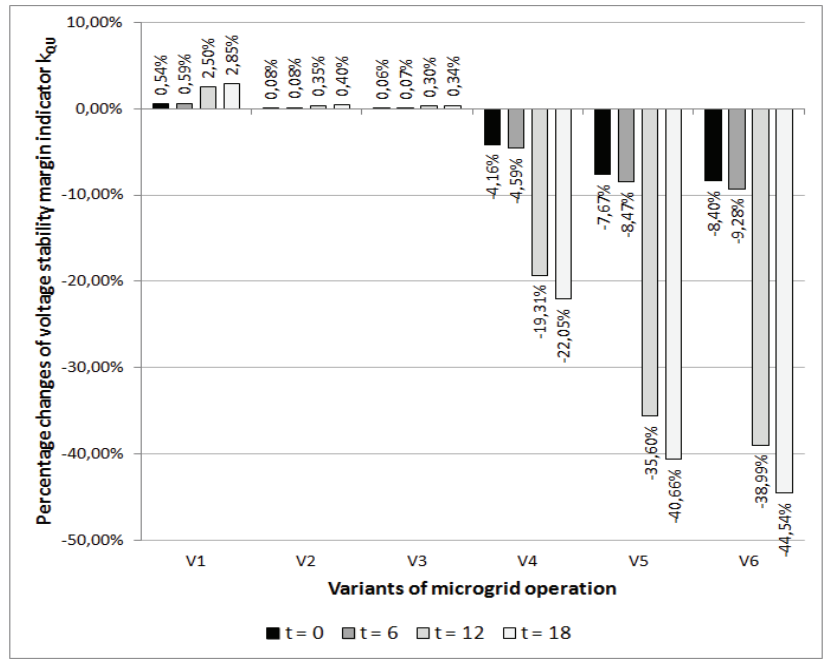

Fig. 11. Percentage changes in the indicator $k_{Q U}$ value of node $N 35$ depending on the chosen microgrid operation variant in relation to $\mathrm{V} 0$ variant

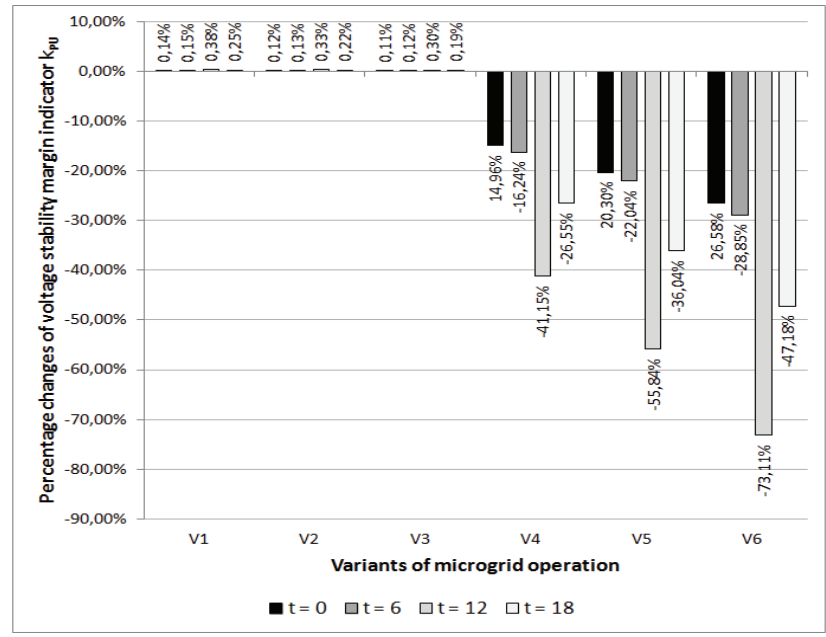

Fig. 12. Percentage changes in the indicator $k_{P U}$ value of node $N 20$ depending on the chosen microgrid operation variant in relation to $\mathrm{V} 0$ variant

Additionally, diagram was prepared (Fig. 14) showing the nose curves for node N35 (variant V3).

From the data presented in the attached diagrams it can be seen that if microgrid is connected to the network of DSO, reduction of power generated in microsoures has a little effect on voltage stability margin of microgrid. When microgrid operates in island mode the effect of reducing generated power is more visible. The data presented in Figure 14 indicate that:

- impact of active power load only on voltage level is greater than impact of reactive power load only (for high power values), 
- for low power values $(P<100 \mathrm{~kW} \vee Q<100 \mathrm{kVar})$ the situation is different. The difference may result from the changing power factor value during the loading process,

- trends of changes in case of $U(Q)$ and $U(P)$ curves designated for the load with constant power factor are identical,

- the lowest value of voltage just before loss of voltage stability appears is achieved in case of active power load only, which confirms the dominant influence of active power on voltage level in low voltage grids,

- the worst conditions of voltage stability are in case of constant power factor load, however, the obtained values do not differ significantly from the case of active power load only.

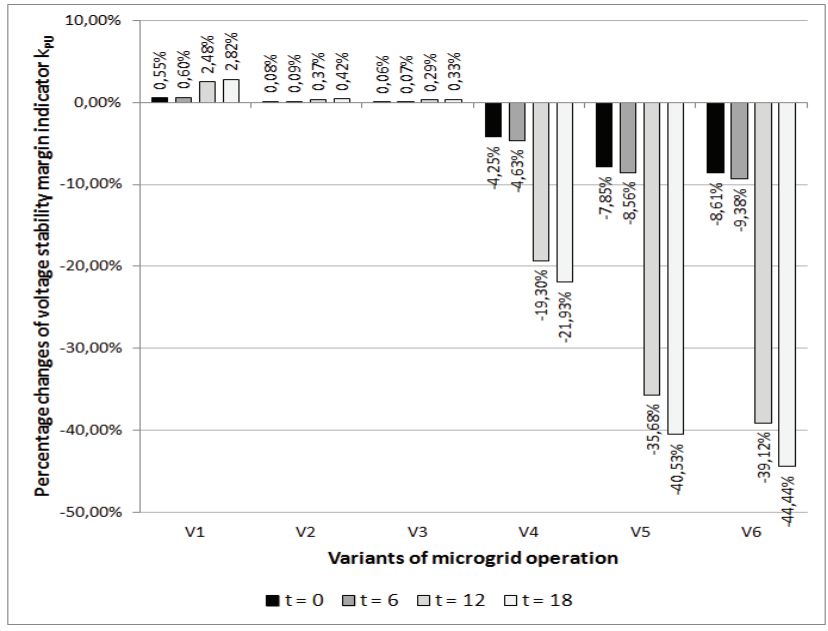

Fig. 13. Percentage changes in the indicator $k_{P U}$ value of node $N 35$ depending on the chosen microgrid operation variant in relation to $\mathrm{V} 0$ variant

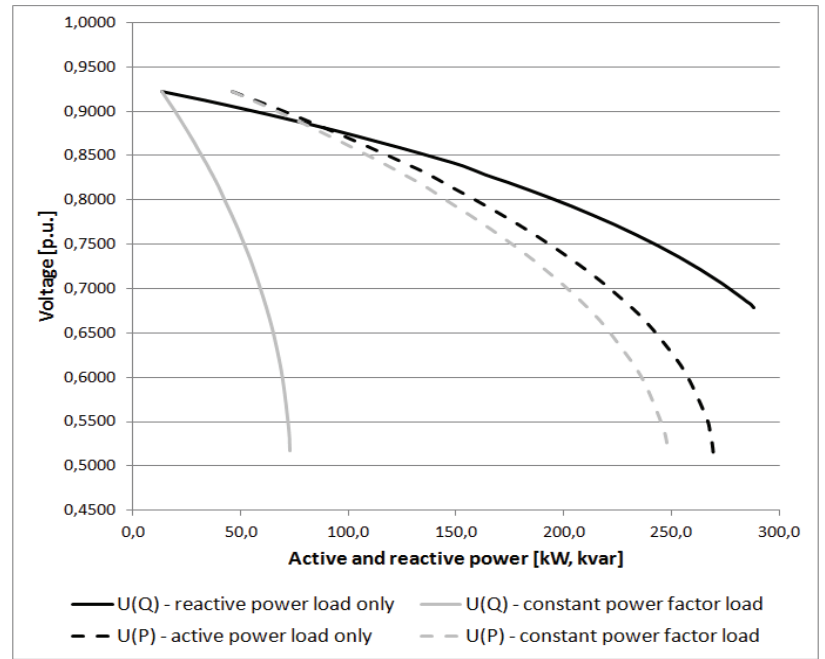

Fig. 14. Nose curves for node N35 - variant V3 


\section{Summary and conclusions}

It should be noted that a method of loading of microgrid nodes has a significant impact on the values of voltage stability margin indicators.

In cooperation with the network of DSO mode, when the node is loaded with active power only or with constant power factor the values of corresponding to this indicators are much lower than in case of reactive power load only. The reason of this phenomenon is much greater value of $\mathrm{LV}$ network resistance, according to its reactance.

In island mode the situation is different, $k_{P U}$ index calculated in case of active power load only is much bigger than in other cases.

The difference between the values of voltage stability margin indicators in cooperation with the network of DSO and in island mode result from changing operation conditions of microgrid during the transition from one mode to another. In parallel with network of DSO mode there is a large reserve of supply of active and reactive power (critical values are similar). Very low value of $k_{Q U}$ index in island mode results from the large gap between active and reactive power supply reserves (reactive power reserves are approximately one order of magnitude smaller than the reserves of active power). The reason of this difference are the settings of diesel power generator controller. The adopted control strategy assumes that diesel power generation set will not be loaded more than the rated values and active power needed to balance the microgrid will be delivered from energy storage unit.

The calculations of voltage stability margin made in the test microgrid allow for drawing the following conclusions:

- the usage of microsources connected in parallel to the network of DSO may result in the improvement of the microgrid voltage stability,

- the voltage stability margin of the microgrid operating in the island mode is much lower due to limited ability of generation of reactive power by microsources,

- the used indicators of voltage stability margin are determined based on the current load of node with active and reactive power and are characterized by large daily fluctuations,

- values of both examined indicators in case of active or reactive power load only are different,

- in case of constant power factor load both indicators have similar values regardless of microgrid operation mode,

- the voltage values as well as values of active power and reactive power at which the voltage stability is lost (especially when microgrid is connected to the network of DSO) are large enough to destroy the equipment from which the microgrid consists of long before reaching the point of voltage stability loss,

- gradual loss of power of the gas microturbine results in the decrease of the voltage stability margin of the microgrid,

- the greatest differences between the voltage stability indicators depending on the microgrid operating variant may be seen in nodes N30-N41 (the nodes are included in the line that connects the microturbine with the LV switchgear in the transformer substation). In other microgrid nodes the influence of power changes of microturbine was smaller. 
Natural application areas of LV microgrids are industrial zones and residential estates. Microgrids can also provide power to small villages and tourist settlements located in difficult to access areas or on islands. Increasing the number of microsources, energy storage devices and power electronic converters can improve voltage stability and reliability of energy supplies in this areas. An additional argument for the dissemination of microgrids can be relieving electric power lines and ability to sell excess energy, generated in microsources based on renewable energy sources, to external power system.

Scientific works concerning the issues presented in the paper should be continued. Further investigations should especially refer to optimal selection of microsources and energy storage devices to ensure better voltage stability conditions of microgrids. Another issue for further investigations, is a long-term operation in island mode, especially important for microgrids built in areas with poorly developed infrastructure of power grids.

\section{Acknowledgements}

Authors of the paper thank Ph.D. E. Eng. Krzysztof Księżyk for granting permission to use in carried out research the low voltage microgrid diagram and the microgrid data, which are described in [14].

\section{References}

[1] Lasseter R., Akhil A., Marnay Ch. et al., White Paper on Integration of Distributed Energy Resources: The CERTS MicroGrid Concept. [Online]. Available: http://certs.lbl.gov/pdf/50829.pdf, accessed April (2002).

[2] Hatziargyriou N.D., Asano A., Iravani R. et al., IEEE Power \& Energy Magazine 4(5): 78-94 (2007).

[3] Kroposki B., Lasseter R., Ise T. et al., Making microgrids work. IEEE Power \& Energy Magazine 3(6): 41-53 (2008).

[4] Hatziargyriou N.D., Dimeas A.L., Tsikalakis A.G. et al., Management of microgrids in market environment. CD Proc. of the Int. Conf. on Future Power Systems, Amsterdam, 7 pp., (2005).

[5] Katiraei F., Iravani R., Hatziargyriou N.D., Dimeas A.L., Microgrids management. Control and operation aspects of microgrids. IEEE Power \& Energy Magazine 3(6): 54-65 (2008).

[6] Parol M., Księżyk K., Optimum control in microgrids. Pendrive Proc. of the Second Int. Youth Conf. on Energetics, Budapest, 6 pp., (2009).

[7] Parol M., Wójtowicz T., Optimization of Exchange of Electrical Energy between Microgrid and Electricity Utility Distribution Network. CD Proc. of the Int. Symposium on Modern Electric Power Systems - MEPS‘10, Wrocław, 6 pp., (2010).

[8] Machowski J., Regulation and stability in electric power system. Warsaw, Publishing House of Warsaw University of Technology (2007), in Polish.

[9] Majumder R., Some aspects of stability in microgrids. IEEE Transactions on Power Systems 3(28): 3243-3252 (2013).

[10] Tamersi A., Radman G., Aghazadeh M., Enhancement of microgrid dynamic voltage stability using microgrid voltage stabilizer. Southeastcon, 2011 Proceedings of IEEE, Nashville, pp. 368-373 (2011).

[11] Niranen J., Komsi R., Routimo M. et al., Experiences from a back-to-back converter fed village microgrid. Proc. of the Conf. on Innovative Smart Grid Technologies Conference Europe (ISGT Europe), Gothenburg, pp. 1-5 (2010).

[12] Papathanassiou S., Hatziargyriou N.D., Strunz K., A benchmark low voltage microgrid network. Proc. of the CIGRE Symposium on Power Systems with Dispersed Generation, Athens, 8 pp., (2005).

[13] PowerFactory v. 14.1. Manual (DIgSILENT Technical Documentation).

[14] Księżyk K., Parol M., Steady states analysis of micro-grids operation. Przegląd Elektrotechniczny (Electrical Review) 11(84): 14-19 (2008).

[15] Rokicki Ł., Voltage Stability in LV microgrids, Master Thesis (in Polish). Faculty of Electrical Engineering, Warsaw University of Technology (2013). 